\title{
Heat Transfer Reduction due to a Ceiling-Mounted Barrier in an Enclosure with Natural Convection
}

\author{
Gamze Gediz Ilis, Moghtada Mobedi \& Hakan F. Öztop
}

To cite this article: Gamze Gediz llis, Moghtada Mobedi \& Hakan F. Öztop (2011) Heat Transfer Reduction due to a Ceiling-Mounted Barrier in an Enclosure with Natural Convection, Heat Transfer Engineering, 32:5, 429-438, DOI: 10.1080/01457632.2010.483889

To link to this article: http://dx.doi.org/10.1080/01457632.2010.483889

\section{Published online: 13 Oct 2011.}

\section{Submit your article to this journal $\square$}

Џ Article views: 114

Q View related articles $\square$

Citing articles: 5 View citing articles 5 


\title{
Heat Transfer Reduction due to a Ceiling-Mounted Barrier in an Enclosure with Natural Convection
}

\author{
GAMZE GEDIZ ILIS, ${ }^{1}$ MOGHTADA MOBEDI, ${ }^{1}$ and HAKAN F. ÖZTOP ${ }^{2,3}$ \\ ${ }^{1}$ Department of Mechanical Engineering, Izmir Institute of Technology, Izmir, Turkey \\ ${ }^{2}$ Department of Mechanical Engineering, Technology Faculty, Firat University, Elazig, Turkey \\ ${ }^{3}$ Department of Mechanical Engineering, College of Engineering, King Saud University, Riyadh, Saudi Arabia
}

\begin{abstract}
Effects of a ceiling-mounted barrier on natural convection heat transfer in a square cavity with differentially heated wall are numerically investigated. A limit case, in which the partition has small thickness and low thermal conductivity, is studied. The study is performed for nine different locations of barrier on the ceiling, two different lengths of barrier as 15 and $50 \%$ of the side wall, and Rayleigh numbers from $10^{3}$ to $10^{6}$. The vorticity and streamfunction approach is used to obtain velocity distribution, and the energy equation is solved to determine temperature field in the cavity. The variations of the local Nusselt number on the hot and cold walls and the change of mean Nusselt number with the location of barrier in the cavities with different Rayleigh numbers are presented. The obtained results show that a wall-mounted barrier can be used to reduce heat transfer rate through the cavity; however, its effectiveness depends on length and location of barrier and Rayleigh number.
\end{abstract}

\section{INTRODUCTION}

The phenomenon of heat transfer by natural convection in enclosures has significant interest due to the wide variety of applications such as cooling of electronic devices, thermal energy storage, solar collectors, nuclear reactors, and heating and cooling of buildings. Natural convection occurs in any fluid region in that a body force and temperature gradient exist. A comprehensive review on the applications of natural convection has been reported by Ostrach [1], Catton [2], Jaluria [3], and Vahl Davis and Jones [4].

Most of the previous works have addressed natural convection in differentially or partially heated rectangular or nonrectangular-shaped enclosures without any partition. However, a partition (or partitions) can be used as a control parameter to reduce or enhance heat transfer and flow strength inside an enclosure [5-7]. The enclosures can be divided by a partition hanging from the top wall or extending from the bottom floor [8-11] or both [12-14] or from side walls [15-20]. The thermal state of the partition plays an important role on the heat and fluid flow in a cavity. Thermally, a partition behaves between two limiting cases. The partition may be made of highly

Address correspondence to Professor Moghtada Mobedi, Department of Mechanical Engineering, Izmir Institute of Technology, 35430, Urla, Izmir, Turkey. E-mail: moghtadamobedi@iyte.edu.tr conductive materials, and thus the partition temperature will be at the temperature of the mounted wall [9-10, 12-18], or the thermal conductivity of partition may be very low, and thus no temperature gradient exists between the partition surfaces and adjacent fluid $[7,8]$. The present study is focused on the effects of the latter partition, meaning that the thermal conductivity of partition is very low compared to the fluid thermal conductivity. This is a limiting case for which heat cannot flow through the fin. Moreover, the thickness of the fin is not considered as an independent parameter and its thickness is assumed small compared to the width of the cavity.

A literature survey shows that there are limited studies on the effects of fins, partitions, or barriers on heat and fluid flow in a cavity. Varol et al. [8,9] used partitions to control heat transfer and fluid flow inside a right-angle triangular enclosure. They found that the location of partitions changes the number of circulation cells and temperature distribution. Oztop and Bilgen [10] and Dagtekin and Oztop [11] investigated the effects of heated or cooled partitions mounted onto bottom wall of square enclosures. Other examples of their studies can be found in references [13] and [14]. In the context of location of partitions onto two walls, studies were performed and reported in references [15] and [16]. In the studied cases, a jet-like flow is formed between partitions due to the narrow region, and strength of flow is decreased. A numerical analysis was performed on natural 
convection in a square cavity with a thin baffle on the hot wall by Tasnim and Collins [16]. They found that a fin has a blocking effect on the fluid depending on the Rayleigh number, length of the baffle, and its position, and a number of recirculating regions can be formed above and under the baffle. Heat transfer in a differentially heated square cavity due to a thin fin on the hot wall was studied by Shi and Khodadadi [17]. They indicated that the heat transfer capacity on the anchoring wall is always degraded by introducing a fin; however, heat transfer on the cold wall without a fin can be promoted for high Rayleigh numbers and with the fins placed closer to the insulated walls. Bilgen $[18,19]$ made a numerical analysis to investigate the transition phenomenon of laminar to turbulent flow in the partially divided enclosures. He found that the flow regime is laminar for Rayleigh number up to $10^{8}$. Nag et al. [20] analyzed an enclosure that has a perfectly conducting partition and they found that the heat transfer at the cold wall increased irrespective of the position or length of the conducting partition. In the study of Frederick [21], the partition was located on the cold side wall of the enclosure. Moukalled and Acharya [22] performed a numerical investigation on natural convection heat transfer in partially divided trapezoidal cavities. The effects of Rayleigh number, baffle height, and baffle location on heat transfer in summerlike and winter-like conditions in their work were studied. The effect of baffles on heat and fluid flow in trapezoidal cavities under different baffle locations and cavity thermal conditions can also be found in their other studies [23, 24].

Visualization of both heat and fluid flow helps researchers to see the effects of partition or barrier in a cavity. Although the flow visualization can be done using streamlines, the imagination of heat transfer path in a convective flow is not easy. Heatline technique was first proposed by Kimura and Bejan [25] to visualize convective heat transfer, and the method has been extended to different applications by Morega and Bejan [26], Dash [27], Dalal and Das [28], and Costa [29]. A detailed review study on the applications of heatlines was performed by Costa [30]. Recently, heatline methods (or Bejan's heatline) were applied on different problems of natural convections in porous or fluid filled enclosures [31-37]. Mobedi [31] and Hakyemez et al. [36] performed studies on conjugate natural convection heat transfer in cavities, and they indicated that the heatline visualization is a powerful method to show the heat interaction between solid and fluid at an interface. Transient natural convection in a cylindrical enclosure heated nonuniformly at the top wall was studied numerically by Aggarwal et al. [37]. They used heatline techniques, and the obtained results showed that the unicellular motion degenerates into a multicellular motion, resulting in the stratification of the temperature field in the axial direction.

In this literature survey, no study was found on analyzing of heat transfer reduction by a single and insulated partition mounted on the top wall of a rectangular enclosure and on employing heatline technique to visualize heat flow in a cavity with the presence of a barrier. The aim of the present study is to investigate the effects of a ceiling-mounted barrier on heat and fluid in a differentially heated air-filled cavity. The heatline

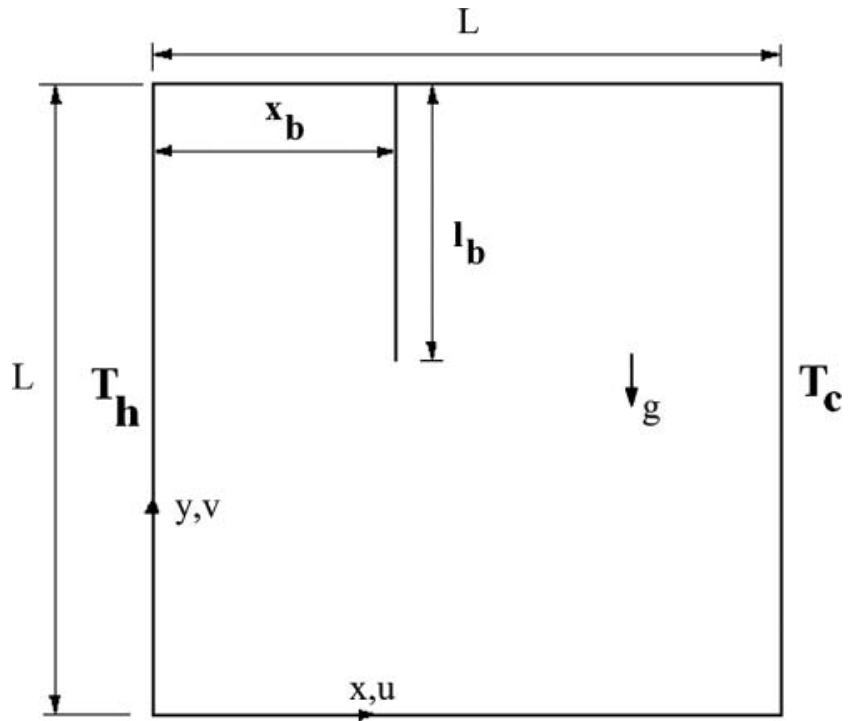

Figure 1 Schematic view of the cavity analyzed in the present study.

visualization technique is employed to demonstrate the path of heat transfer. There is no doubt that the considered barrier reduces the heat transfer rate between the hot and cold walls; however, the rate of decrease depends on the location and length of the barrier and Rayleigh number. The variations of local and average Nusselt numbers on the hot and cold walls with location and length of barrier for different values of Rayleigh numbers are also discussed.

\section{THE CONSIDERED PROBLEM}

The schematic view of the cavity and barrier with the employed coordinate is shown in Figure 1. The cavity has a square cross section with side length of $\mathrm{L}$. The left wall is at a high temperature $\left(T_{h}\right)$, whereas the right wall is maintained at a low temperature $\left(\mathrm{T}_{\mathrm{c}}\right)$. The upper and lower walls are adiabatic. Heat is transferred from the left to right wall by natural convection. Radiation mode of heat transfer is neglected. The thermal conductivity of barrier is very low compared to the fluid thermal conductivity, and the thickness of barrier is small compared to the width of cavity. The thickness and length of the vertical barrier are $w_{b}$ and $\ell_{b}$, and the dimensionless length and thickness of the barrier are defined as $L_{b}=\ell_{b} / L$ and $W_{b}=w_{b} / L$. The dimensionless location of the barrier on the ceiling wall is identified by $X_{b}$, which refers to the distance of the base of barrier from left top corner of cavity as seen in Figure 1. In the same way, the dimensionless location of barrier is $X_{b}=x_{b} / L$. Hence, the value of $X_{b}$ varies between 0 and 1 . Heat and fluid flow is steady and the problem is solved for air with $\operatorname{Pr}=0.71$.

\section{GOVERNING EQUATIONS AND BOUNDARY CONDITIONS}

The steady behavior of flow and temperature distribution is investigated in this study. The steady solution of the governing 
equations can be obtained from the solution of either the steady or transient form of the governing equations. The latter approach is generally known as the time marching approach. In fact, there is no difference between the steady results of the two approaches when the solution of the governing equations is unique. The governing equations for the problem are continuity, momentum, and energy equations. The gravity acts in the negative vertical direction. The pressure term in the momentum equation can be eliminated using a vorticity-streamfunction approach. The use of dimensionless vorticity and streamfunction parameters yields the dimensionless form of the governing equations as follows:

$$
\begin{aligned}
& \frac{\partial \Omega}{\partial \tau}+\frac{\partial U \Omega}{\partial \mathrm{X}}+\frac{\partial V \Omega}{\partial \mathrm{Y}}=\operatorname{Pr}\left(\frac{\partial^{2} \Omega}{\partial \mathrm{X}^{2}}+\frac{\partial^{2} \Omega}{\partial \mathrm{Y}^{2}}\right)+\operatorname{RaPr} \frac{\partial \theta}{\partial \mathrm{X}} \\
& \frac{\partial^{2} \Psi}{\partial \mathrm{X}^{2}}+\frac{\partial^{2} \Psi}{\partial \mathrm{Y}^{2}}=-\Omega \\
& \frac{\partial \theta}{\partial \tau}+\frac{\partial U \theta}{\partial \mathrm{X}}+\frac{\partial V \theta}{\partial \mathrm{Y}}=\frac{\partial^{2} \theta}{\partial \mathrm{X}^{2}}+\frac{\partial^{2} \theta}{\partial \mathrm{Y}^{2}}
\end{aligned}
$$

where $\mathrm{U}, \mathrm{V}, \theta, \tau, \mathrm{X}$ and $\mathrm{Y}$ are dimensionless parameters:

$\mathrm{X}=\frac{x}{L}, Y=\frac{y}{L}, U=\frac{u L}{\alpha}, V=\frac{v L}{\alpha}, \theta=\frac{\left(T-T_{\mathrm{c}}\right)}{\left(T_{\mathrm{h}}-T_{\mathrm{c}}\right)}, \tau=\frac{\alpha \mathrm{t}}{L^{2}}$

The dimensionless vorticity, streamfunction, and Rayleigh number are defined as:

$$
\begin{aligned}
\Omega & =\frac{\partial \mathrm{V}}{\partial \mathrm{X}}-\frac{\partial \mathrm{U}}{\partial \mathrm{Y}} \\
\mathrm{U} & =\frac{\partial \Psi}{\partial \mathrm{Y}}, \mathrm{V}=-\frac{\partial \Psi}{\partial \mathrm{X}} \\
\mathrm{Ra} & =\frac{\mathrm{g} \beta\left(\mathrm{T}_{\mathrm{h}}-\mathrm{T}_{c}\right) \mathrm{L}^{3}}{\nu \alpha}
\end{aligned}
$$

The boundary conditions for the domain that is shown in Figure 1 can be written as follows:

$\mathrm{X}=0, \mathrm{X}=1 ; \Omega=\frac{\partial \mathrm{V}}{\partial \mathrm{X}}, \Psi=0, \theta(0, \mathrm{Y}, \tau)=1, \theta(1, \mathrm{Y}, \tau)=0$

$$
\mathrm{Y}=0, \mathrm{Y}=1 ; \Omega=-\frac{\partial \mathrm{U}}{\partial \mathrm{Y}}, \frac{\partial \theta}{\partial \mathrm{Y}}=\Psi=0
$$

The boundary conditions for the surface of barrier with dimensionless thickness as $W_{b}$ are:

$\mathrm{X}=X_{b}-W_{b} / 2, \mathrm{X}=X_{b}+W_{b} / 2$ when $1-\mathrm{L}_{\mathrm{b}}<\mathrm{Y}<1$;

$$
\frac{\partial \theta}{\partial \mathrm{X}}=U=V=0, \Omega=\frac{\partial \mathrm{V}}{\partial \mathrm{X}}
$$

The finite-difference form of boundary condition for vorticity at the tip of the barrier was written according to the method explained by Poulikakos and Kimura in reference [38]. The value of vorticity at a solid wall can be calculated from the values of streamfunction at the solid wall and adjacent nodes, or it can directly be calculated from the gradient of velocity in normal direction. The latter method provides acceptable results when sufficient number of nodes is used. The comparison between the results of present code and reported studies on natural convection in a square cavity shows this fact. As it was mentioned before, the steady results are our interest, and the obtained results should not depend on initial condition. For simplicity, the following initial conditions for dimensionless temperature, vorticity, and streamfunction are used:

$$
\mathrm{U}=\mathrm{V}=\Omega=\Psi=\theta=0
$$

The dimensionless form of the governing equations and boundary conditions reduce number of dimensionless parameters to four, which are $\operatorname{Ra}, \operatorname{Pr}, L_{b}$, and $X_{b}$. The present study is performed for air with $\operatorname{Pr}=0.71$; therefore, the effects of three dimensionless parameters, which are Rayleigh number, dimensionless length of barrier, and dimensionless location of barrier, are taken into account.

The following equation is solved to obtain dimensionless heatfunction [26-28]:

$$
\frac{\partial^{2} H}{\partial \mathrm{X}^{2}}+\frac{\partial^{2} H}{\partial \mathrm{Y}^{2}}=\frac{\partial U \theta}{\partial \mathrm{Y}}-\frac{\partial V \theta}{\partial \mathrm{X}}
$$

The dimensionless heatfunction in differential form is defined as:

$$
-\frac{\partial \mathrm{H}}{\partial \mathrm{X}}=V \theta-\frac{\partial \theta}{\partial Y}, \frac{\partial \mathrm{H}}{\partial \mathrm{Y}}=U \theta-\frac{\partial \theta}{\partial X}
$$

The boundary conditions for Eq. (12) are obtained from the integration of Eq. (13) along the considered boundary. For example, the dimensionless heatfunction values at $\mathrm{X}=0$ and $\mathrm{X}=$ 1 boundaries are determined as [28]:

For $X=0$ and $0<Y \leq 1$ :

$$
H(0, Y)=H(0,0)-\int_{0}^{Y} \frac{\partial \theta}{\partial X} d Y
$$

For $X=1$ and $0<Y \leq 1$ :

$$
H(1, Y)=H(1,0)-\int_{0}^{Y} \frac{\partial \theta}{\partial X} d Y
$$

For the lower and upper horizontal walls and the surface of the barrier, which are adiabatic,

$$
H=\text { const. }
$$

At the origin, the value of heatfunction is considered as zero, $\mathrm{H}(0,0)=0$.

\section{SOLUTION PROCEDURE}

The governing equations (Eqs. (1)-(3)) are solved by starting from an initial state. The vorticity equation is solved for a time 
step to compute the vorticity field in the computational domain. Then the streamfunction equation is solved and the velocity values are obtained from the streamfunction field. At the same time step and by using the new values of velocity, the energy equation is solved and the temperature field is computed. The procedure is continued until the steady state is reached. The energy and vorticity equations are solved line by line by employing an alternating direction implicit (ADI) method, whereas the streamfunction equation is solved point by point. The finitedifference forms of diffusion and convection terms are written based on three points central difference, which has second-order accuracy. For iterations concerning solution of the streamfunction equation (Eq. (2)) at each time step and the solution of dimensionless heatfunction equation (Eq. (12)), the following convergence criterion is used:

$$
\frac{\sum\left|\varphi^{m+1}-\varphi^{m}\right|}{\sum\left|\varphi^{m}\right|} \leq 10^{-8}
$$

where $\varphi$ represents the value of streamfunction and heatfunction for all the nodes inside computational domain, and $m$ shows a step of iteration. The convergence criterion for the outer iteration, which yields the steady state solution for velocity and temperature fields, is defined as:

$$
\frac{\sum\left|\theta^{n+1}-\theta^{n}\right|}{\Delta \tau \sum \theta^{n}} \leq 10^{-4}
$$

where $n$ shows a time step for outer iteration and $\Delta \tau$ is the interval time. The local Nusselt number on the cold and hot walls and the average Nusselt number values are calculated by the following equations:

$$
\begin{aligned}
& \mathrm{Nu}=-\left.\frac{\partial \theta}{\partial \mathrm{X}}\right|_{\text {wall }} \\
& \bar{N} u=\int_{\mathrm{Y}=0}^{\mathrm{Y}=1} \mathrm{NudY}
\end{aligned}
$$

In order to investigate the effectiveness of a heat barrier on reduction of heat transfer rate through the cavity, a dimensionless parameter as Nusselt number ratio (NNR) can be introduced [17].

$$
N N R=\frac{\bar{N} u_{\text {withbarrier }}}{\bar{N} u_{\text {withoutbarrier }}}
$$

The values of NNR greater than 1 show the enhancement of heat transfer in the cavity, whereas NNR values less than 1 indicate reduction of heat transfer through the cavity. Nonuniform mesh grid sizes were used, and the grid sizes were selected fine near the walls and the barrier. The studies performed on the variation of Nusselt number with number of nodes and comparison between the obtained numerical results with reported studies in literature show that $210 \times 210$ for the number of nodes is sufficient to obtain acceptable numerical results. The smallest dimensionless grid spacing was in the fluid region adjacent to the barrier, as 0.001 .

\section{Validation}

To check the written computer code and to validate the employed method, Table 1 is presented. The results of Shi and Khodadadi [17], Bilgen [18], and Vahl Davis and Jones [4] for a differentially heated air-filled square cavity are obtained and compared with the results of the present study for different Rayleigh numbers of $10^{3}, 10^{4}, 10^{5}$, and $10^{6}$. Moreover, another validation study was performed by comparison of the maximum absolute value of streamfunction for different Rayleigh numbers. The comparison of the streamfunction results is presented in Table 2. Good agreement between the obtained results from the written code and the results reported in literature can be seen from Tables 1 and 2. In order to check the drawn heatlines, the heatline patterns for a square cavity with differential wall temperatures when $\mathrm{Ra}=10^{5}$ are plotted and compared with heatline patterns reported in the study of Basak and Roy [34]. As seen from Figure 2, there is an excellent agreement between the drawn heatline patterns and the reported one. It should be mentioned that for the all obtained results, the values of Nusselt number for the hot and cold walls were very close to each other, signifying the satisfaction of energy conservation.

\section{RESULTS AND DISCUSSION}

The effects of the barrier on the temperature and velocity fields are shown via isotherms, streamlines, and heatlines for different governing parameters. Figure 3 is presented to show the effects of location of a short-length barrier $\left(L_{b}=0.15\right)$ on the temperature and velocity fields for $\mathrm{Ra}=10^{3}$ and for three barrier locations as $X_{b}=0.125,0.50$, and 0.875 . The isotherms and streamlines are presented on the left and middle,

Table 1 The benchmark solution based on mean Nusselt number

\begin{tabular}{lcccc}
\hline Rayleigh number & Present study & Shi and Khodadadi [17] & Bilgen [18] & $\begin{array}{c}\text { de Vahl Davis and Jones } \\
\text { [4] }\end{array}$ \\
\hline $10^{3}$ & 1.11 & - & - & 1.25 \\
$10^{4}$ & 2.24 & 2.25 & 4.52 & 2.24 \\
$10^{5}$ & 4.51 & 4.53 & 8.80 & 4.52 \\
$10^{6}$ & 8.80 & 8.89 & 8.80 \\
\hline
\end{tabular}




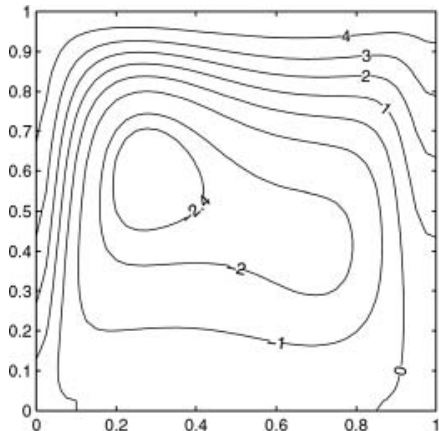

(a)

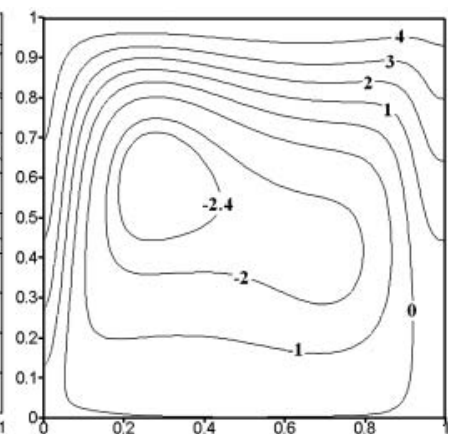

(b)
Figure 2 Comparison of heatline patterns in a square cavity with $\mathrm{Ra}=10^{5}$ : (a) heatline patterns reported by Basak and Roy [34], and (b) heatline patterns of the present study.

while the heatlines are on the right of Figure 3. The conduction heat transfer is dominant in the cavity because of low Rayleigh number. The isotherms are almost parallel to each other and to the vertical isothermal walls. Single circulation cell occurs in the clockwise direction as shown from the streamlines. In this case, the barrier has little effect on the heat and fluid flow patterns. The direction of heat flow at the top region of the cavity is changed due to the presence of a heat barrier. A region in the center of the cavity exists in where heat only rotates without playing a role on the transfer of heat from the hot to the cold wall.

Figure 4 shows the effects of a long barrier $\left(L_{b}=0.50\right)$ on the isotherms (on the left), streamlines (in the middle), and heatlines (on the right) for the barrier location as $X_{b}=0.125,0.50$, and 0.875 when $\mathrm{Ra}=10^{3}$. Again, the isotherms are almost parallel to each other due to the dominant conduction heat transfer; however, the increase of barrier length considerably influences the streamline patterns. For the cavities with barrier at $X_{b}=$ 0.125 an almost stagnant region appears between the barrier and left wall. A similar stagnant region is also observed between the barrier and the right wall for $X_{b}=0.875$ barrier location. For barrier location at $X_{b}=0.5$, the hot air in the left region of the cavity flows toward the ceiling, but it cannot continue its horizontal motion due to the presence of the barrier. It flows down and after passing from the edge region of the barrier, it again moves up and continues its motion to the cold wall. A bean-shaped main cell was formed due to presence of the barrier. Figure 4 also shows that the long barrier affects the heatline patterns. Similar to the fluid flow, for the barrier location at $X_{b}$ $=0.50$, heat flows in horizontal direction, then moves down,

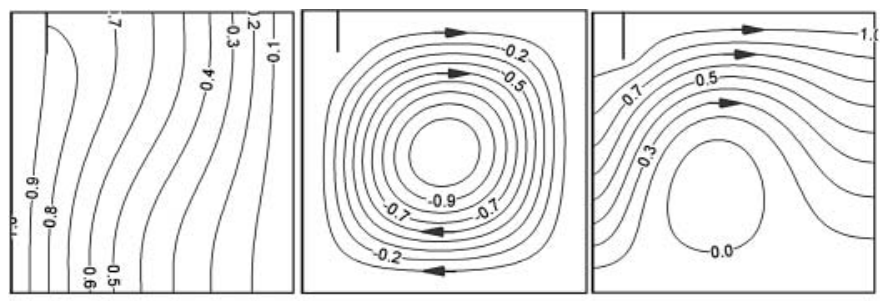

(a)

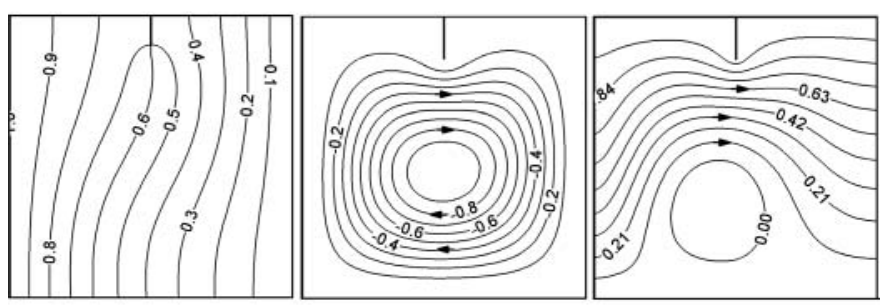

(b)

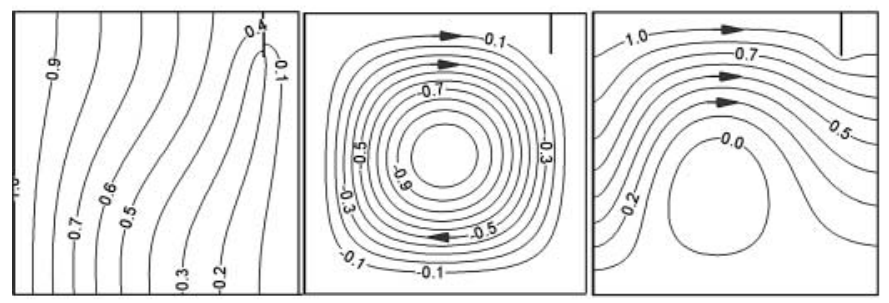

(c)

Figure 3 The isotherms (on the left), streamlines (in the middle), and heatlines (on the right) in a cavity with $\mathrm{L}_{\mathrm{b}}=0.15$ and $\mathrm{Ra}=10^{3}$ : (a) $\mathrm{X}_{\mathrm{b}}=0.125$, (b) $\mathrm{X}_{\mathrm{b}}$ $=0.5$, and (c) $\mathrm{X}_{\mathrm{b}}=0.875$.

and after passing the edge of barrier it flows toward the cold wall. A passive heat transfer area in where heat only rotates is seen in the cavity with $X_{b}=0.875$.

Figure 5 shows the isotherms (on the left), streamlines (in the middle), and heatlines (on the right) for the cavity with barrier as $L_{b}=0.50$ and three locations of barrier $\left(X_{b}=0.125,0.50\right.$, $0.875)$ when $\mathrm{Ra}=10^{6}$. The increase of the Rayleigh number enhances the strength of convection heat transfer, and as a result, the isotherms become parallel to the horizontal walls. The long barrier distorts the patterns of fluid flow. The distortion can be clearly seen from the streamline patterns in the cavity with barrier location of $X_{b}=0.50$. The barrier changes the direction of the fluid flow in the upper region of the cavity and increases the path flow length. For the same cavity, the barrier also affects the heatline patterns and increases the length of heat flow path.

Table 2 The comparison of the maximum absolute values of streamfunction

\begin{tabular}{lccc}
\hline $\begin{array}{l}\text { Rayleigh } \\
\text { number }\end{array}$ & $\begin{array}{c}\text { Present study } \\
\left|\psi_{\max }\right|\end{array}$ & $\begin{array}{c}\text { Catton [2] } \\
\left|\psi_{\max }\right|\end{array}$ & $\begin{array}{c}\text { Jaluria [3] } \\
\left|\psi_{\max }\right|\end{array}$ \\
\hline $10^{3}$ & 1.17 & - & - \\
$10^{4}$ & 5.07 & 5.08 & - \\
$10^{5}$ & 9.60 & 9.60 & 9.61 \\
$10^{6}$ & 16.77 & 17.04 & 16.75 \\
\hline
\end{tabular}




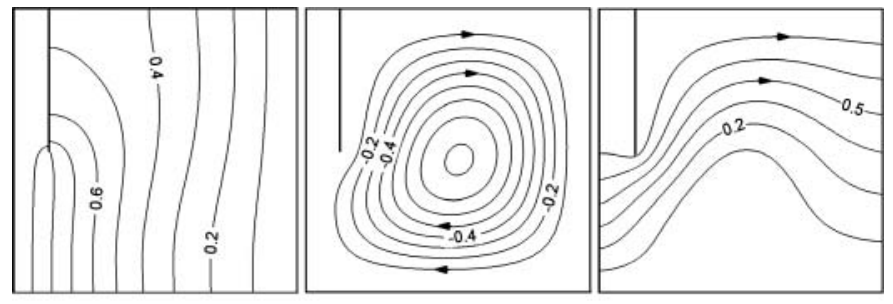

(a)

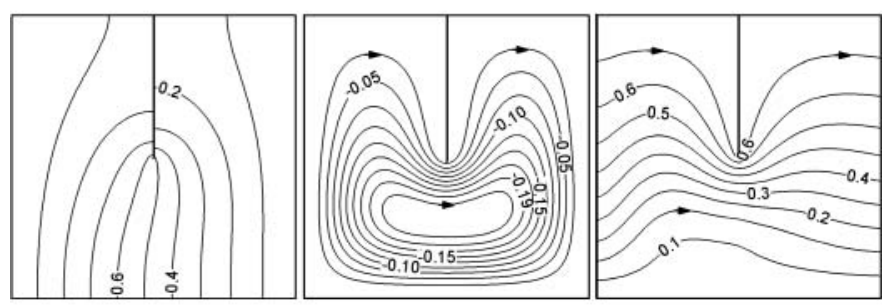

(b)

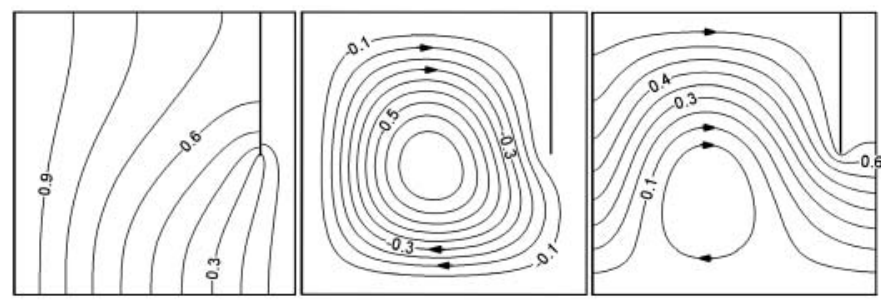

(c)

Figure 4 Isotherms (on the left), streamlines (in the middle), and heatlines (on the right) in a cavity with $\mathrm{L}_{\mathrm{b}}=0.5$ and $\mathrm{Ra}=10^{3}$ : (a) $\mathrm{X}_{\mathrm{b}}=0.125$, (b) $\mathrm{X}_{\mathrm{b}}=0.5$, and (c) $\mathrm{X}_{\mathrm{b}}=0.875$.

The value of heatfunction at the large region in the center of cavity is negative, signifying the rotation of heat in that region.

Figure 6 shows the heatline patterns in cavities with $L_{b}=$ 0.50 and the barrier location of $X_{b}=0.50$ for Rayleigh numbers of $10^{3}, 10^{4}, 10^{5}$, and $10^{6}$. For the cavity with $\mathrm{Ra}=10^{3}$, the heatlines are almost parallel to each other, resembling adiabatic distributions in a solid region. The increase of Rayleigh number to $\mathrm{Ra}=10^{4}$ enhances convection transport and the hot air flows upward, but it cannot flow horizontally due to the barrier. After passing from the edge of heat barrier, it again flows upward. The increase of convection effect can be clearly seen by increasing the Rayleigh number to $10^{5}$ and $10^{6}$. The heatlines in the region close to the hot and cold walls become closer to each other, signifying increase of convection in the $\mathrm{Y}$ direction. For $\mathrm{Ra}=$ $10^{4}, 10^{5}$, and $10^{6}$, cells in where heat rotates form in the center of cavity. These regions, colored by gray in Figure 6, are passive regions and do not play a role on the heat transfer from the hot to the cold wall. The increase of Rayleigh number increases the passive region area and heatline clusters on the vertical walls of the cavity.

The variation of local Nusselt number on the hot and cold walls for different locations of the barrier for a cavity with $\mathrm{Ra}=$ $10^{6}$ and $\mathrm{L}_{\mathrm{b}}=0.50$ are shown in Figure 7. As seen from Figure $7 \mathrm{a}$, for the barrier located at $X_{b}=0$, the local Nusselt number at

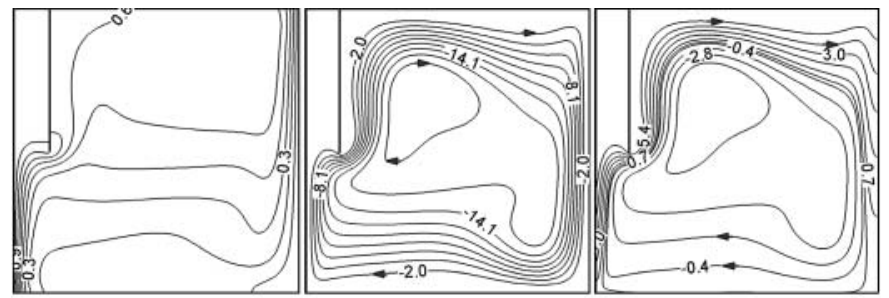

(a)

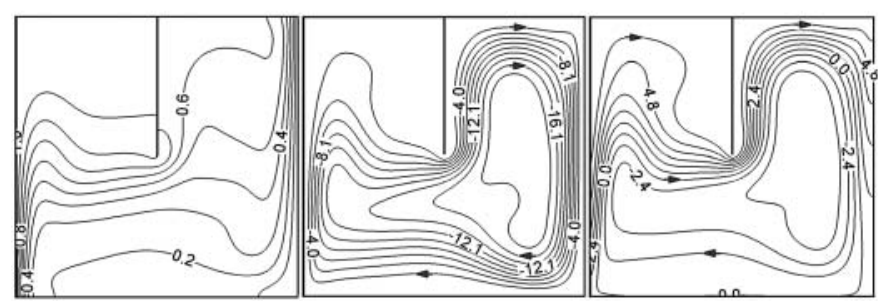

(b)

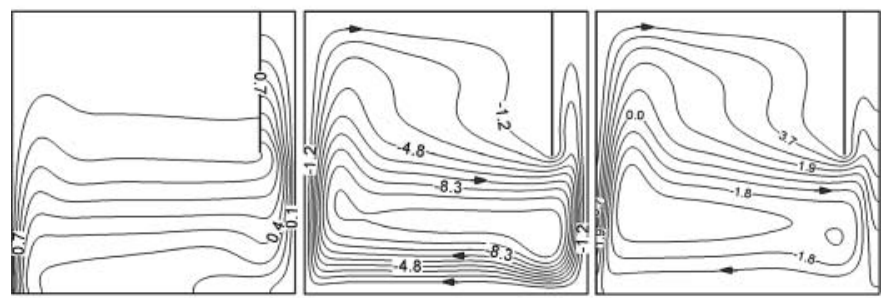

(c)

Figure 5 The isotherms (on the left), streamlines (in the middle), and heatlines (on the right) in a cavity with $\mathrm{L}_{\mathrm{b}}=0.5$ and $\mathrm{Ra}=10^{6}$ : (a) $\mathrm{X}_{\mathrm{b}}=0.125$, (b) $\mathrm{X}_{\mathrm{b}}$ $=0.5$, and (c) $\mathrm{X}_{\mathrm{b}}=0.875$.

the left wall increases in the $+Y$ direction, attains a maximum, and then starts to decrease. At $Y=0.50$, which is the end of the heated wall, a jump in the local Nusselt number is seen because the upward flow along the wall is cooled by the cold fluid in the upper space. Thus, the temperature at the end of the heated wall falls and temperature gradient becomes steep at that location. The values of the local Nusselt number on the left wall for $X_{b}$ $=0$ after $Y=0.50$ location are zero due to the presence of the barrier on the hot wall. The variation of local Nusselt number on the hot wall is changed by changing the location of the barrier from $X_{b}=0$ to $X_{b}=0.125$. The local Nusselt number increases in the $+Y$ direction, attains a maximum, and then starts to decrease. For $Y>0.60$, the local Nusselt number is almost zero due to stagnant hot region between the hot wall and barrier. The change of barrier from $X_{b}=0.125$ to $X_{b}=0.50$ results in the easier movement of the fluid in the $+Y$ direction in the right region of the cavity. As a result, the local Nusselt number increases in the $+\mathrm{Y}$ direction and then it monotically decreases in the $+Y$ direction. The same variation is also observed for the local Nusselt number of the hot wall in the cavity with the barrier location as $X_{b}=0.875$ and 1.00 . It should be mentioned that the variations of local Nusselt number for $X_{b}=0.875$ and 1.00 barrier locations are almost identical. As expected, when the barrier is close to the hot wall, the variation of the local Nusselt 


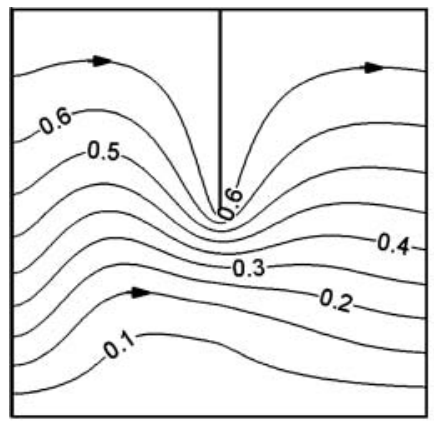

a)

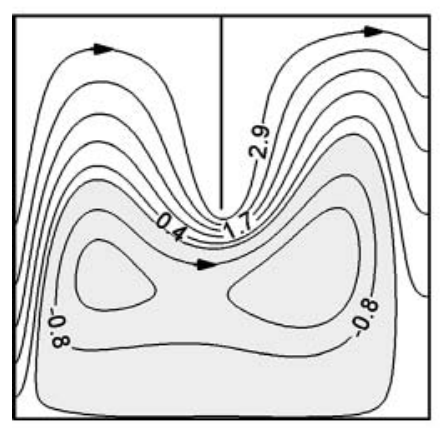

c)

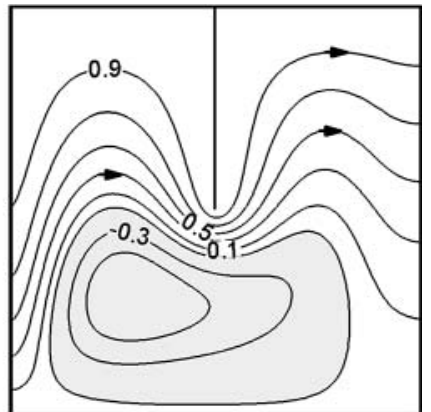

b)

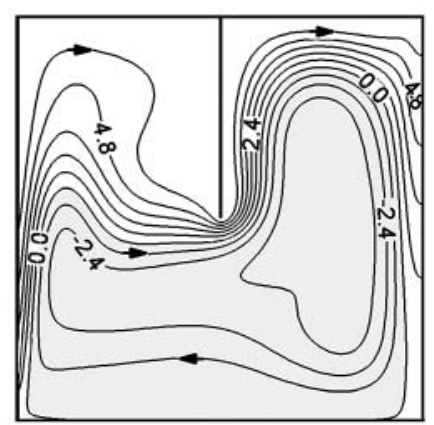

d)
Figure 6 Heatline patterns in a cavity with $\mathrm{L}_{\mathrm{b}}=0.5$ and $\mathrm{X}_{\mathrm{b}}=0.5$ : (a) $\mathrm{Ra}=$ $10^{3}$, (b) $\mathrm{Ra}=10^{4}$, (c) $\mathrm{Ra}=10^{5}$, and (d) $\mathrm{Ra}=10^{6}$.

number at the hot wall is highly influenced by the presence of the barrier. The effect of the barrier on the variation of the local Nusselt number at the hot wall becomes smaller by changing the location of barrier toward the cold wall.

The variation of local Nusselt number of the cold wall for different barrier location is shown in Figure $7 \mathrm{~b}$. The variation of local Nusselt number at the cold wall for barrier location as $X_{b}=0,0.125$, and 0.50 are almost similar to each other. The variations of local Nusselt number on the cold wall are almost the same for $X_{b}=0$ and 0.125 barrier locations in Figure $7 \mathrm{~b}$. However, it is changed when the barrier is placed at $X_{b}=0.875$. When the barrier is close to the right wall (e.g., $X_{b}=0.875$ ), the value of local Nusselt number at the upper part of the right wall is small due to the stagnant region between the barrier and the cold wall. For the barrier location at $X_{b}=1.0$, the local Nusselt number is zero in the region $0.5<Y<1.0$ and a jump of local Nusselt number is seen at $Y=0.50$, and then it decreases in the $-Y$ direction. The jump of local Nusselt number at $Y=$ 0.50 is due to the high temperature gradient between the hot air flowing down and the edge of the cooled wall.

The variations of the average Nusselt number in the cavity with $L_{b}=0.15$ for different Rayleigh numbers are shown in Figure 8a. As is seen, for the short barrier, the average Nusselt number is not greatly changed with the barrier location. The small changes of average Nusselt number are seen for $\mathrm{Ra}=$ $10^{6}$. For the cavity with $\mathrm{Ra}=10^{6}$ and $L_{b}=0.15$, the highest Nusselt number is seen for $X_{b}=0.50$ as $\mathrm{Nu}=8.756$, and the lowest value of Nusselt number is observed for the barrier

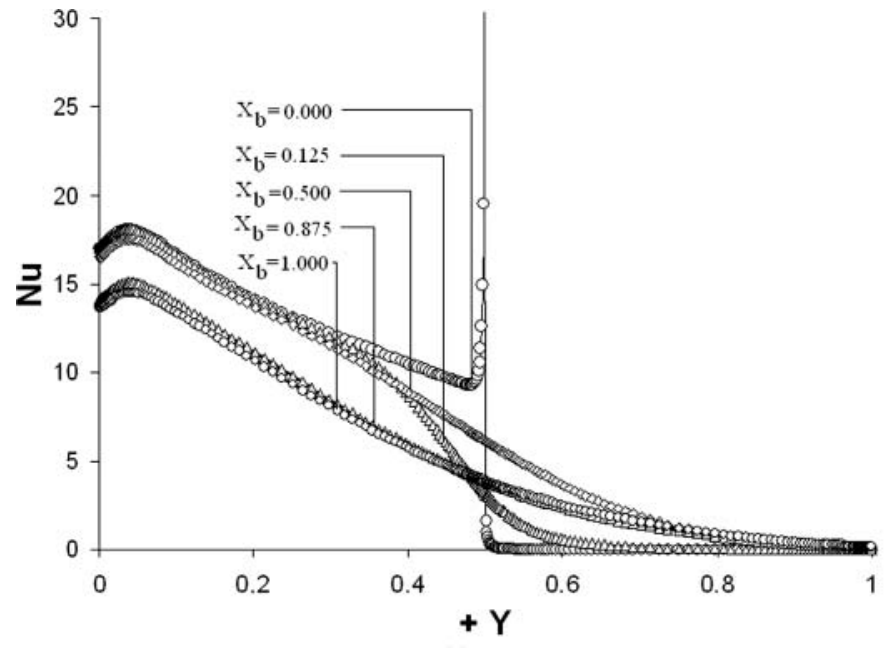

(a)

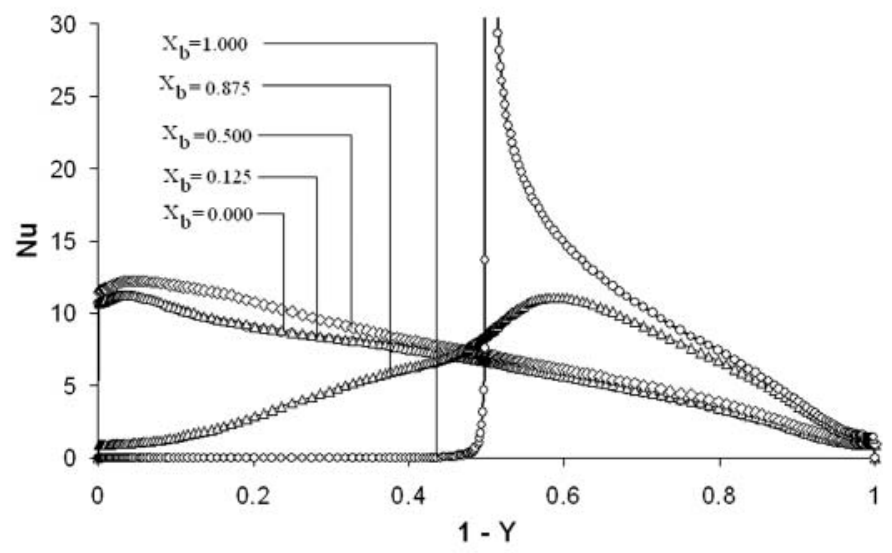

(b)

Figure 7 The variation of local Nusselt number at the vertical walls of a cavity with $\mathrm{Ra}=10^{6}$ for different barrier locations: (a) hot wall, and (b) cold wall.

location at $X_{b}=1.00$ as $\mathrm{Nu}=8.240$. For the barrier location of $X_{b}=1.00$ and $L_{b}=0.15$, the barrier reduces the heat transfer rate through the cavity by $6.4 \%$ if it is compared to the heat transfer through the cavity without barrier. The value of NNR for this position of the barrier is 0.936 .

The changes of the average Nusselt number with barrier location for different Rayleigh numbers when $L_{b}=0.50$ is shown in Figure 8b. The increase of the barrier length increases its effect on the heat transfer through the cavity. For the cavity with $\mathrm{Ra}=10^{3}$, the heat transfer through the cavity is slightly changed with the barrier location. The minimum Nusselt number is observed at $X_{b}=0.50$ as $\mathrm{Nu}=0.705$. Heat transfer rate is considerably changed with the barrier location for $\mathrm{Ra}=10^{6}$. For the cavity with $\mathrm{Ra}=10^{6}$, the minimum Nusselt number is seen for $X_{b}=1.00$ barrier location, as $\mathrm{Nu}=5.44$.

The variation of the Nusselt Number Ratio with barrier location for a cavity with $L_{b}=0.50$ and different values of Rayleigh numbers is presented in Figure 9. As is seen, the values of NNR for different locations and Rayleigh numbers are less than 1 , 


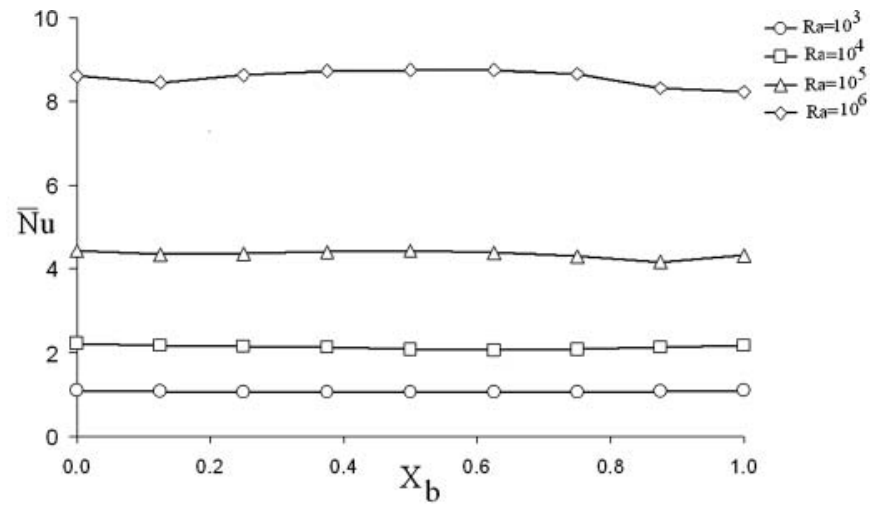

(a)

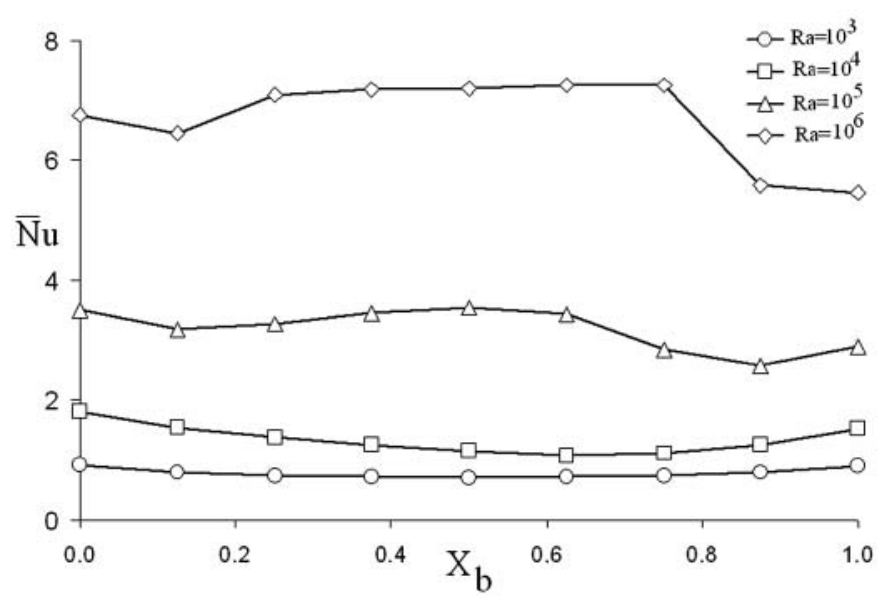

(b)

Figure 8 The variation of average Nusselt number with barrier location for different Rayleigh numbers: (a) short-length barrier $L_{b}=0.15$, and (b) longlength barrier $L_{b}=0.50$.

signifying the reduction of heat transfer rate through the cavity if a barrier is mounted on the top wall of the cavity. For $\mathrm{Ra}=10^{3}$, the minimum value of NNR is observed for $X_{b}=0.50$ barrier location as 0.64. The increase of Rayleigh number increases the effectiveness of the barrier and the minimum value of NNR is found to be 0.477 for $X_{b}=0.625$ and $\mathrm{Ra}=10^{4}$. The increase of Rayleigh number from $10^{4}$ to $10^{5}$ reduces the effectiveness of the barrier, since the fluid flow becomes stronger. The minimum value of NNR is seen at $X_{b}=0.875$, which is 0.569 when Ra $=10^{5}$. Further increase of Rayleigh number increases the value of NNR, and the minimum NNR value is observed for $X_{b}=$ 1.0 barrier location as 0.619 when $\mathrm{Ra}=10^{6}$. The location of the heat barrier on the cold wall directly reduces the active part of the cold wall by $50 \%$. As seen from Figure 9 , the best location of the barrier for maximum reduction of heat transfer through a cavity depends on the Rayleigh number. The best location of barrier for maximum reduction of heat transfer is shifted from the middle of cavity to the cold wall with the increase of Rayleigh number.

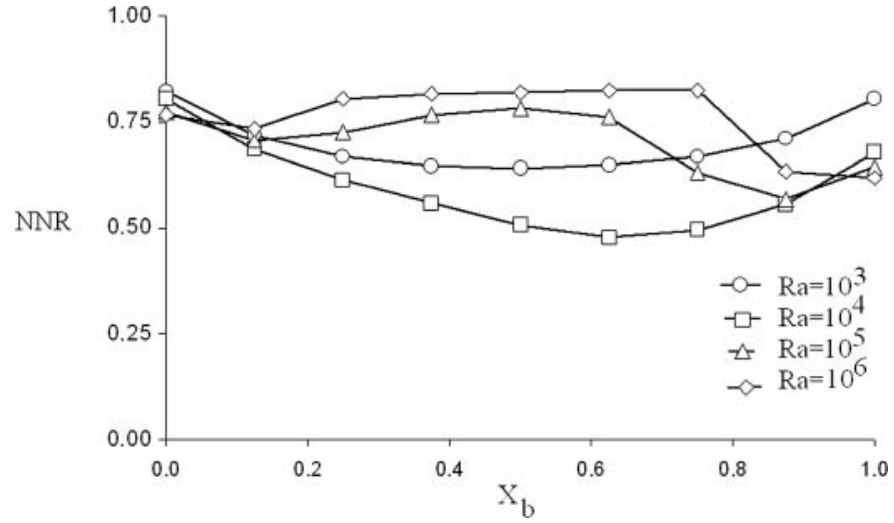

Figure 9 The variation of Nusselt number ratio with barrier location for different values of Rayleigh number when $L_{b}=0.50$.

\section{CONCLUSIONS}

The effect of a barrier mounted on the ceiling of a square cavity on heat transfer through the cavity is numerically studied. The present study investigates a limit case in which thermal conductivity of barrier is very low and the barrier has small thickness compared to the width of cavity. The ceiling-mounted barrier reduces heat transfer rate through a cavity; however, its effect highly depends on length and location of the barrier and on the Rayleigh number. The increase of barrier length increases its influence on heat and fluid flow in the cavity. For the cavity with $\mathrm{Ra}=10^{6}$, the heat transfer rate through the cavity is considerably changed with the barrier location and the minimum $\bar{N} u$ is observed for barrier location at the $\mathrm{X}=1.0$. A long barrier $\left(L_{b}=0.50\right)$ at the $X_{b}=1.00$ location reduces heat transfer rate by $38 \%$.

The Nusselt number ratio is defined to show the effectiveness of the barrier. The highest barrier effect is found for the cavity with $L_{b}=0.50, X_{b}=0.625$, and $\mathrm{Ra}=10^{4}$. For the high values of Rayleigh number (i.e., $\mathrm{Ra}=10^{6}$ ), fluid flow becomes stronger and the effect of the barrier on the heat transfer rate through the cavity becomes smaller. For the cavity with low Rayleigh number (i.e., $\mathrm{Ra}=10^{3}$ ), maximum reduction of heat transfer is achieved when the barrier is located in the middle of the ceiling. By increase of the Rayleigh number, the location of barrier should be shifted to the cold wall in order to have maximum reduction of heat transfer.

A heatline visualization technique is employed to show heat flow from the hot to cold wall. For low Rayleigh number (i.e., $\mathrm{Ra}=10^{3}$ ), heatline patterns do not cluster in a region, and a cell (i.e., passive region) in which heat only rotates is observed. The increase of Rayleigh number enhances the strength of the fluid flow, and the heatlines are clustered in the regions close to the vertical walls. The increase of the Rayleigh number also increases the area of the passive region in the cavity. 


\section{NOMENCLATURE}

g acceleration due to gravity, $\mathrm{m} / \mathrm{s}^{2}$

$H$ dimensional heatfunction

L height and length of cavity, $m$

$L_{b} \quad$ dimensionless barrier length

$\ell_{b} \quad$ barrier length, $\mathrm{m}$

NNR Nusselt number ratio

$\mathrm{Nu} \quad$ local Nusselt number

$\bar{N} u \quad$ average Nusselt number

$\mathrm{Ra} \quad$ Rayleigh number

Pr Prandtl number

$\mathrm{T}$ temperature, $\mathrm{K}$

$\mathrm{t}$ time, $\mathrm{s}$

$\mathrm{u}, \mathrm{v} \quad$ velocities, $\mathrm{m} / \mathrm{s}$

$\mathrm{U}, \mathrm{V}$ dimensionless velocities

w thickness, $\mathrm{m}$

W dimensionless thickness

$\mathrm{x}, \mathrm{y}$ dimensional coordinates, $\mathrm{m}$

$\mathrm{X}, \mathrm{Y}$ dimensionless coordinates

$X_{b} \quad$ dimensionless location of barrier on the ceiling

\section{Greek Symbols}

$\alpha \quad$ thermal diffusivity, $\mathrm{m}^{2} / \mathrm{s}$

$v \quad$ kinematic viscosity, $\mathrm{m}^{2} / \mathrm{s}$

$\beta \quad$ thermal expansion coefficient, $\mathrm{K}^{-1}$

$\theta \quad$ dimensionless temperature

$\Psi \quad$ dimensionless streamfunction

$\Omega \quad$ dimensionless vorticity

$\tau \quad$ dimensionless time

\section{Subscripts}

h hot wall

c cold wall

b barrier

\section{REFERENCES}

[1] Ostrach, S., Natural Convection in Enclosures, ASME Journal of Heat Transfer, vol. 110, pp. 1175-1190, 1988.

[2] Catton, I., Natural Convection in Enclosures, Proc. 6th Int. Heat Transfer Conf., Toronto, Canada, vol. 6, pp. 13-43, 1978.

[3] Jaluria, Y., Natural Convection Heat and Mass Transfer, Pergamon Press, Oxford, UK, pp. 209-235, 1980.

[4] De Vahl Davis, G., and Jones, L.P., Natural Convection in a Square Cavity: A Comparison Exercise, International Journal for Numerical Methods in Fluids, vol. 3, pp. 227-248, 1983.

[5] Nansteel, M. W., and Greif, R., Natural Convection in Undivided and Partially Divided Rectangular Enclosures, Journal of Heat Transfer, vol. 103, pp. 623-629, 1981.

heat transfer engineering
[6] Nansteel, M. W., and Greif, R., An Investigation of Natural Convection in Enclosures with Two and Three Dimensional Partitions, International Journal of Heat and Mass Transfer, vol. 27, pp. 561-571, 1984.

[7] Kelkar, K. M., and Patankar, S. V., Numerical Prediction of Natural Convection in Square Partitioned Enclosures, Numerical Heat Transfer, Part A: Applications, vol. 17, pp. 269-285, 1990.

[8] Varol, Y., Oztop, H. F., and Varol, A., Effects of Thin Fin on Natural Convection in Porous Triangular Enclosures, International Journal of Thermal Sciences, vol. 46, pp. 1033-1045, 2007.

[9] Varol, Y., Oztop, H. F., and Yilmaz, T., Natural Convection in Triangular Enclosures With Protruding Isothermal Heater, International Journal of Heat and Mass Transfer, vol. 50, pp. 2451-2462, 2007.

[10] Oztop, H., and Bilgen, E., Natural Convection in Differentially Heated and Partially Divided Square Cavities With Internal Heat Generation, International Journal of Heat and Fluid Flow, vol. 27, pp. 466-475, 2006.

[11] Dagtekin, I., and Oztop, H. F., Natural Convection Heat Transfer by Heated Partitions Within Enclosure, International Communications in Heat and Mass Transfer, vol. 40, pp. 823-834, 2001.

[12] Facas, G. N., Natural Convection in a Cavity with Fins Attached to Both Vertical Walls, Journal of Thermophysics and Heat Transfer, vol. 4, pp. 555-560, 1993.

[13] Dagtekin, I., Öztop, H. F., and Inallı, M., An Investigation on Natural Convection in a Cavity Divided by Partition, Simer'2000, 6th National Heating Cooling and Air Conditioning Congress, pp. 138-145, Adana, Turkey, 2000 (in Turkish).

[14] Dagtekin, I., and Oztop, H. F., A Numerical Study in an Enclosure With Adiabatic Block Mounted on Side Wall, Dokuz Eylul University Engineering Journal, vol. 4, pp. 53-62, 2002 (In Turkish).

[15] Yucel, N., and Ozdem, A. H., Natural Convection in Partially Divided Square Enclosure, Heat and Mass Transfer, vol. 40, pp. 167-175, 2003.

[16] Tasnim, S. H., and Collins, M. R., Numerical Analysis of Heat Transfer in a Square Cavity With a Baffle on the Hot Wall, International Communications in Heat and Mass Transfer, vol. 31, pp. 639-650, 2004.

[17] Shi, X., and Khodadadi, J. M., Laminar Convection Heat Transfer in a Differentially Heated Square Cavity Due to a Thin Fin on the Hot Wall, Journal of Heat Transfer, vol. 125, pp. 624-634, 2003.

[18] Bilgen, E., Natural Convection in Cavities With a Thin Fin on the Hot Wall, International Journal of Heat and Mass Transfer, vol. 48, pp. 3493-3505, 2005.

[19] Bilgen, E., Natural Convection in Enclosures with Partial Partitions, Renewable Energy, vol. 26, pp. 257-270, 2002.

[20] Nag, A., Sarkar, A., and Sastri, V. M. K., Natural Convection in a Differentially Heated Square Cavity With a

vol. 32 no. 52011 
Horizontal Partition Plate on the Hot Wall, Computer Methods in Applied Mechanical Engineering, vol. 110, pp. 143-156, 1993.

[21] Frederick, R. L., Natural Convection in an Inclined Square Enclosure With a Partition Attached to Its Cold Wall, International Journal of Heat and Mass Transfer, vol. 32, pp. 87-94, 1989.

[22] Moukalled, F., and Acharya, S., Buoyancy-Induced Heat Transfer in Partially Divided Trapezoidal Cavities, $\mathrm{Nu}$ merical Heat Transfer, Part A: Applications, vol. 32, pp. 787-810, 1997.

[23] Moukalled, F., and Acharya, S., Natural Convection in Trapezoidal Cavities With Baffles Mounted on the Upper Inclined Surfaces, Numerical Heat Transfer, Part A: Applications, vol. 37, pp. 545-565, 2000.

[24] Moukalled, F., and Acharya, S., Natural Convection in a Trapezoidal Enclosure With Offset Baffles, Journal of Thermophysics and Heat Transfer, vol. 5, pp. 212-218, 2001

[25] Kimura, S., and Bejan, A., The Heatline Visualization of Convective Heat Transfer, Journal of Heat Transfer, vol. 105, pp. 916-919, 1983.

[26] Morega, A. M., and Bejan, A., Heatline Visualization of Forced Convection Laminar Boundary Layers, International Journal of Heat and Mass Transfer, vol. 36, pp. 3957-3966, 1993.

[27] Dash, S. K., Heatline Visualization in Turbulent Flow, International Journal of Numerical Methods for Heat \& Fluid Flow, vol. 6, pp. 37-46, 1996.

[28] Dalal, A., and Das, M. K., Heatline Method for the Visualization of Natural Convection in a Complicated Cavity, International Journal of Heat and Mass Transfer, vol. 51, pp. 263-272, 2008.

[29] Costa, V. A. F., Unified Streamline, Heatline and Massline Methods for the Visualization of Two-Dimensional Heat and Mass Transfer in Anisotropic Media, International Journal of Heat and Mass Transfer, vol. 46, pp. 1309-1320, 2003.

[30] Costa, V. A. F., Bejan's Heatlines and Masslines for Convection Visualization and Analysis, Applied Mechanics Reviews, vol. 59, pp. 126-145, 2006.

[31] Mobedi, M., Conjugate Natural Convection Heat Transfer in a Square Cavity With Finite Thickness Horizontal Walls, International Communications in Heat and Mass Transfer, vol. 35, pp. 503-513, 2008.

[32] Basak, T., Roy, S., and Pop, I., Heat Flow Analysis for Natural Convection Within Trapezoidal Enclosures Based on Heatline Concept, International Journal of Heat and Mass Transfer, vol. 52, pp. 2471-2483, 2009.

[33] Basak, T., Aravind, G., and Roy, S., Visualization of Heat Flow due to Natural Convection Within Triangular Cavities Using Bejan's Heatline Concept, International Journal of Heat and Mass Transfer, vol. 52, pp. 2824-2833, 2009.

[34] Basak, T., and Roy, S., Role of 'Bejan's Heatlines' in Heat Flow Visualization and Optimal Thermal Mixing for Dif- ferentially Heated Square Enclosures, International Journal of Heat and Mass Transfer, vol. 51, pp. 3486-3503, 2008.

[35] Mahmud, S., Fraser, R. A., and Pop, I., Flow, Thermal, Energy Transfer, and Entropy Generation Characteristics Inside Wavy Enclosures Filled With Microstructures, Journal of Heat Transfer, vol. 129, pp. 1564-1575, 2007.

[36] Hakyemez, E., Mobedi M., and Oztop H. F., Effects of Wall-Located Heat Barrier on Conjugate Conduction/Natural-Convection Heat Transfer and Fluid Flow in Enclosures, Numerical Heat Transfer, Part A: Applications, vol. 54, pp. 197-220, 2008.

[37] Aggarwal, S. K., and Manhapra, A., Transient Natural Convection in a Cylindrical Enclosure Nonuniformly Heated at the Top Wall, Numerical Heat Transfer, Part A: Applications, vol. 15, pp. 341-356, 1989.

[38] Bejan, A., Convection Heat Transfer, John Wiley and Sons, New York, 1984.

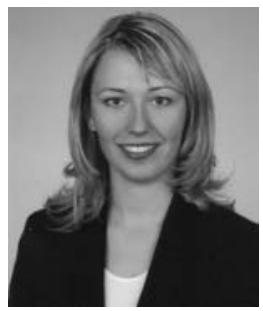

Gamze Gediz Ilis is a Ph.D. student in the Mechanical Engineering Department at Izmir Institute of Technology (IYTE), Turkey. She obtained her bachelor's degree in 2001 from the Mechanical Engineering Department of Dokuz Eylul University. She received her first M.S. degree in 2004 from the Mechanical Engineering Department of IYTE, and she received her second M.S. degree from the Engineering Management Department of the same university in 2006. She worked with product responsibility in the marketing department of an HVAC company between 2004 and 2007. She studies adsorption heat pumps, heat and mass transfer in adsorbents, and zero-energy houses.

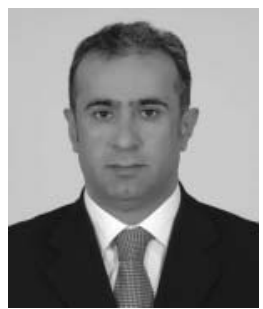

Moghtada Mobedi is an associate professor in the Mechanical Engineering Department of Izmir Institute of Technology, Turkey. He received his $\mathrm{Ph} . \mathrm{D}$. from Middle East Technical University in 1994. He worked in an HVAC company as a research and development (R\&D) project manager between 1999 and 2005. His research interests include computational heat and mass transfer, heat and mass transfer in porous media, adsorption heat pumps, and ventilation in cleanrooms. He currently works on natural convection in cavities, and heat and mass transfer in adsorbent beds of adsorption heat pumps. He has published more than 50 papers in journals and conference proceedings.

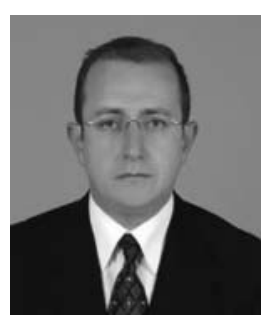

Hakan F. Öztop is an associate professor in the Mechanical Education Department of the Technical Education Faculty of Firat University, Turkey. He received the B.S. degree from Firat University, Department of Mechanical Engineering, in 1996, and the M.Sc. and Ph.D. from the same university in 1998 and 2003, respectively. He has been at Ecole Polytechnique de Montreal, Canada, and Auburn University, USA, as a visiting scholar in 2002 and 2004, respectively. His main research area is numerical heat transfer and fluid flow in forced, mixed, and natural convection through porous ducts and cavities and renewable energy sources. He also has experience in second-law analysis of thermal and fluid systems. He has published more than 80 papers in SCI journals and 60 research articles in international or national conferences.

vol. 32 no. 52011 